\title{
Occupational asthma caused by exposure to neurospora in a plywood factory worker
}

\author{
Johanne Côté, Henry Chan, Gilles Brochu, Moira Chan-Yeung
}

\begin{abstract}
A 24 year old man developed severe asthma two years after starting to work in a plywood plant. Four years later the patient had to stop working because of the increasing severity of his asthma. Three months after leaving his job, the patient's asthma was greatly improved. His job consisted of placing plywood sheets into a drying machine. The plywood sheets had stayed outside in wet conditions for at least four to six weeks and were usually covered with moulds. Drying the plywood sheets changed the mould into a fine orange powder. Exposure to this in the laboratory induced an isolated immediate asthmatic reaction. The same reaction was seen when the patient was challenged with an extract of the mould powder at a $0.1 \%$ $w / v$ concentration. Skin prick test with the mould extract induced a weal and flare reaction and IgE antibodies against the dry mould powder were identified. A control patient with the same degree of bronchial hyperreactivity did not have any asthmatic reaction when challenged with the same mould extract. Culture of the dry mould powder on Sabouraud agar plates grew pure Neurospora sp. This mould has not been previously reported as a cause of occupational asthma. The immunological mechanism is probably related to an IgE mediated mast cell allergy.
\end{abstract}

Moulds have been identified as the aetiological agents in various types of extrinsic allergic alveolitis such as farmer's lung, maple bark lung, bagassosis, and mushroom workers' lung. ${ }^{1-4}$ They have rarely been associated, however, with occupational asthma. ${ }^{5}$ We know of only one report. This

\footnotetext{
Centre de Pneumologie

J Côté

Département de Microbiologie, Hôpital Laval, 2725, chemin Ste-Foy, Sainte-Foy, Québec, Canada G1V 4G5

G Brochu

Department of Medicine, Vancouver General Hospital, 2775, Heather Street, Vancouver, BC, Canada V5Z 3J5

$\mathrm{H}$ Chan, M Chan-Yeung
}

concerned two bakers exposed to Aspergillus and Alternaria species in the work environment who developed sensitisation and asthma from these moulds. ${ }^{6}$ We describe a patient with occupational asthma caused by exposure to the spores of Neurospora sp in a plywood factory.

\section{Case report}

A 24 year old man was first seen in September 1988 for suspected occupational asthma. In 1982 he had started work in a plywood factory that processed hemlock and fir exclusively. His job consisted of putting the wood sheets in the drying machine. The wood sheets were generally stacked outside for four to six weeks before being heat dried and were usually covered with moulds when sent to the dryer. The high temperature transformed the mould into a fine dry powder. As the drying machine was not sealed, the patient was exposed to the mould powder. This patient denied any childhood history or family history of asthma or hay fever. He had no pets at home and was a lifelong non-smoker. After two years of employment in this plywood factory, he began to experience perennial nasal congestion and sneezing. The nasal symptoms did not improve at weekends or on long holidays. A year later, he presented to his family doctor with his first asthma attack and was given salbutamol by inhalation. During the past two years, he noticed a progressive increase in the asthmatic symptoms at work with improvement during long holidays. In June 1988, three months before his first visit to our clinic, he had to leave his job because of the severity of his asthma. Since leaving his asthma symptoms improved. At his visit, his only complaint was increased shortness of breath on heavy exertion. Chest auscultation, chest $x$ ray film, white blood cell count, and differential count were normal. Serum IgE concentration was increased to $2057 \mu \mathrm{g} / \mathrm{ml}$ (normal 0-430). Spirometric measurements and measurement of diffusing capacity were all within normal values. Skin prick tests were done with 25 common aeroallergens. He had positive weal and flare reactions to extracts of cat and feathers.

PREPARATION OF THE MOULD EXTRACTS

About $0.1 \mathrm{~g}$ of mould powder brought to us by the patient was added to phosphate buffered saline (PBS) 
to obtain a $1 \%$ weight/volume ( $w / v)$ mould suspension and stirred overnight at $4^{\circ} \mathrm{C}$. After centrifugation, the supernatant was filtered through a millipore filter and stored at $-20^{\circ} \mathrm{C}$. Dilutions of $1 / 10$ and $1 / 100$ were made and used for the skin prick and specific challenge tests.

\section{PREPARATION OF THE ALLERGEN DISCS FOR RADIOALLERGOSORBENT (RAST) TEST}

The method of coupling of mould extract to paper discs was modified from the method of Ceska et $a l^{7}$. Discs with a diameter of $6 \mathrm{~mm}$ were punched out of Whatman 541 filter papers and 20 washed discs were put in a flask containing $10 \mathrm{ml}$ of distilled water. Cyanogen bromide $(100 \mathrm{mg}$ ) was added to the solution and the $\mathrm{pH}$ was adjusted to 11 for 15 minutes with $1 \mathrm{~N}$ sodium hydroxide. The activated discs were washed in a Buchner funnel with cold distilled water, and then with cold $0.1 \mathrm{M}$ bicarbonate buffer $(\mathrm{pH}$ $8 \cdot 6$ ). Five $\mathrm{ml}$ of the $1 \% \mathrm{w} / \mathrm{v}$ mould extract were added to the activated discs and mixed overnight at $4^{\circ} \mathrm{C}$. The discs were washed five times with cold bicarbonate buffer. Ten $\mathrm{ml}$ of $0.5 \mathrm{M}$ ethanolamine in the same buffer were then added to the discs and mixed at room temperature for two hours. The discs were washed once with bicarbonate buffer, once with $0 \cdot 1 \mathrm{M}$ acetate buffer ( $\mathrm{pH} 4 \cdot 0$ ), three times with PBS and once with RAST buffer (Pharmacon Inc). The discs were stored in RAST buffer at $4^{\circ} \mathrm{C}$ until used.

\section{RADIOALLERGOSORBENT TEST}

A $0.5 \mathrm{ml}$ serum sample was pipetted into a tube containing an allergen disc. The tubes were shaken on a clinical rotator at room temperature for three hours and washed four times with RAST buffer. Then $0.05 \mathrm{ml}$ of ${ }^{125} \mathrm{I}$ labelled goat antihuman $\mathrm{IgE}$ (Pharmacon Inc) was added to each tube and the tubes were incubated at $4^{\circ} \mathrm{C}$ overnight. The next day the tubes were washed four times with RAST buffer and the radioactivity was measured by a $\gamma$-counter. The radioactivity uptake of the allergen discs was expressed as the RAST value-namely, the ratio of the radioactivity of the patient's serum sample to that of a normal control.

\section{MOULD CULTURE}

The dry mould powder was scraped from the wood and suspended in a sterile solution of $\mathrm{NaCl}(0 \cdot 9 \mathrm{~g} / 1)$. This suspension was then cultured on Sabouraud agar plates at $30^{\circ} \mathrm{C}$ for seven days. Microscopical examination of the mould was carried out after staining with lactophenol cotton blue dye.

\section{MEASUREMENT OF BRONCHIAL RESPONSIVENESS}

A methacholine challenge test was done with the Bennett twin nebuliser (output $=0.22 \mathrm{ml} / \mathrm{min}$; median mass diameter $3.0 \mu \mathrm{m}$ ) by our standardised procedure. ${ }^{8}$ The $\mathrm{PC}_{20}$ was obtained by interpolation from the dose response curve drawn on a semilogarithmic non-cumulative scale. Bronchial responsiveness was measured 24 hours before and 24 hours after the specific challenge tests with the mould extract.

\section{SPECIFIC INHALATION CHALLENGE TESTS}

The patient was exposed to the following: day 1: flour (as control); day 2: dry mould powder; day 3: PBS; day 4: mould extract.

Baseline forced expiratory volume in one second $\left(\mathrm{FEV}_{1}\right)$ and forced vital capacity (FVC) were obtained by spirometry using standardised methods as recommended by the American Thoracic Society. ${ }^{910}$ Measurements of peak expiratory flow rate (PEFR) were done using a mini-Wright peak flow meter. The patient was asked to breathe over a bag containing flour for one minute with his eyes covered. The FEV 1 was measured at 30 seconds and 10 minutes after exposure. Inhalation of the flour was for periods of two, five, and 10 minutes until the $\mathrm{FEV}_{1}$ dropped by $20 \%$ from baseline or the 10 minute period was completed. Thereafter an FEV was measured at 10 minute intervals for one hour and hourly for eight hours. The patient was then sent home and asked to measure his PEFR hourly until bedtime and at night if wakened with shortness of breath.

On day 2, the patient was asked to breathe over a bag containing the dry mould powder. He was again blindfolded and used the same protocol as on the control day. On day 3 the patient inhaled PBS for two minutes through a Bennett-twin nebuliser. Following nebulisation, the $\mathrm{FEV}_{1}$ was measured at 30 seconds and at 10 minute intervals for one hour and hourly for eight hours. Peak flow rates were recorded hourly up to bedtime and again at night if the patient was wakened by shortness of breath.

On day 4 the patient was asked to breathe the mould extract at a $1 / 100$ dilution for two minutes; $\mathrm{FEV}_{1}$ was measured at 30 seconds and 10 minutes after inhalation. This was repeated with the $1 / 10$ dilution of mould extract. The inhalation test was stopped after the $\mathrm{FEV}_{1}$ fell by $>20 \%$ with the $1 / 10$ mould extract dilution or the maximum concentration was reached. The FEV 1 and PEFR were measured using the same protocol as on day 3 .

\section{Results}

The day before the specific challenge test, skin prick tests were done with the $1 / 10$ and $1 / 100$ dilution of the mould extract and we saw a $6 \mathrm{~mm}$ and $3 \mathrm{~mm}$ weal and flare reaction respectively. No reaction was seen with the control solution or with extracts of different moulds including Alternaria, Aspergillus fumigatus and terreus, Cladesporium herbarium, Phoma betae, Sporobolomyces, yeast, Candida albicans, and Mesulius lacrymans. The patient also had a metha- 

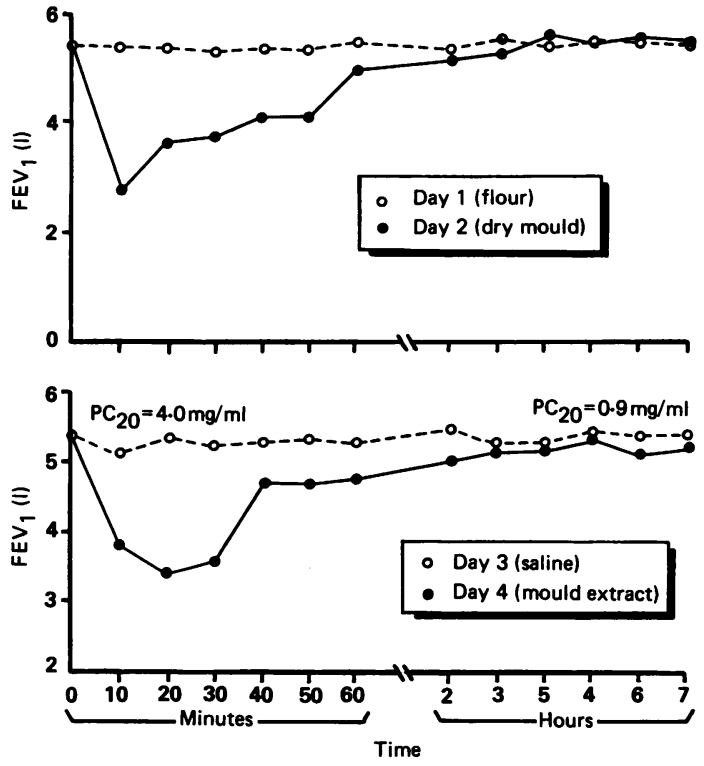

Changes in FEV, over the seven hours spent in the laboratory by the patient on the control day (day 1; exposed to flour), on day 2 (exposed to the crude mould extract), on day 3 (exposed to nebulised PBS), and on day 4 (exposed to the prepared mould extract).

choline challenge test; he had a mild degree of bronchial hyperresponsiveness with a $\mathrm{PC}_{20}$ of $4.9 \mathrm{mg} /$ $\mathrm{ml}$. The figure shows the results of specific challenge tests. On day 1 inhalation of flour did not lead to an appreciable fall in $\mathrm{FEV}_{1}$. On day 2, the patient developed sneezing and nasal congestion after inhaling the dry mould powder for one minute, but no fall in $\mathrm{FEV}_{1}$ was seen. After a further two minutes of inhalation of the dry mould powder, the patient developed cough and wheeze; by this time his FEV had fallen by $49 \%$ from the baseline level. His FEV subsequently improved and returned to normal within one hour. No late reaction was found. On day three, inhalation of PBS and 1/100 dilution of the mould extract for two minutes on day 4 did not induce any asthmatic reaction. On day 4 after the inhalation of the $1 / 10$ dilution of the mould extract for two minutes the patient again developed sneeze and wheeze. His FEV 1 fell by $29 \%$ at 10 minutes after challenge with a further fall to $37 \%$ at 20 minutes followed by a recovery after one hour. No late reaction was seen. The methacholine challenge test was repeated on the morning after the last specific challenge test. Although the $\mathrm{FEV}_{1}$ was not different from the previous day, $\mathrm{PC}_{20}$ methacholine decreased from $4.9 \mathrm{mg} / \mathrm{ml}$ to $0.9 \mathrm{mg} / \mathrm{ml}$.

Diffusing capacity was measured before and after each specific challenge test and was found to be 94, 91 , and $100 \%$ of the predicted value. No increase in
Results of radioallergosorbent tests

\begin{tabular}{lrc}
\hline & Counts/min & RAST value \\
\hline Patient's serum before absorption & 1866 & $16 \cdot 1$ \\
Patient's serum after absorption & 234 & $2 \cdot 0$ \\
Normal serum & 116 & \\
PBS & 130 &
\end{tabular}

* Ratio of the radioactivity of the patient's serum sample to that of normal control.

body temperature was found after the specific challenge tests.

The results of the RAST test are shown in the table. The RAST values for specific IgE antibodies against mould extract before and after absorption with the antigen were 16.1 and 2.0 indicating that the IgE antibodies were specific. The culture on Sabouraud agar plates grew pure Neurospora sp as confirmed by our own laboratory and by the Commonwealth Agricultural Bureau International Mycological Institute.

\section{Discussion}

This report describes a patient who developed occupational asthma from exposure to mould while working in a plywood plant. The features that support the diagnosis of occupational asthma are (1) the absence of history of asthma before working in the plywood factory and (2) the improvement of asthma symptoms when the patient was away from the plywood factory.

We showed by positive skin test and by the presence of specific IgE antibodies to the mould that the patient was sensitised to the mould growing on the plywood. This mould was subsequently identified as Neurospora sp, a mould belonging to the Mucor family. We also showed by inhalation challenge test that the patient had an immediate asthmatic reaction to the mould as well as to an extract of the mould. This mould has not been reported previously as a pathogen for man.

The allergic mechanism in this case is very likely to be a type I allergic reaction as specific IgE antibodies and a positive immediate skin reaction against an extract of the mould were found. Aspergillus and Alternaria species have been reported to be responsible for occupational asthma in two bakers. ${ }^{6}$ Our article reports a third well documented case of occupational asthma due to exposure to mould in the work environment. The fact that the drying machine was not sealed gave the worker a high exposure to the mould powder. Leaving the wood sheets outside for a shorter period, to prevent the growth of the mould before processing, could prevent this type of occupational asthma.

Moulds have been described as the aetiological agents responsible for allergic alveolitis and it is not known why some moulds give rise to allergic 
alveolitis and others to asthma. Possibly the size of the mould dust is important in determining where the site of reaction in the lungs will be. The antigenic determination of the mould may also be an important factor in determining the type of immunological reaction. Finally, the atopic state of the patient may also favour a Type I allergic reaction. Alternaria gives rise to asthma in some subjects and allergic alveolitis in others. Unlike allergic bronchopulmonary aspergillosis, eosinophilia and pulmonary infiltration were not found in our patient.

Our patient is also unusual as he had an increase in bronchial responsiveness after the development of an isolated immediate asthmatic reaction. There was no change in airway calibre to explain this change in $\mathrm{PC}_{20}$ methacholine. It is possible that he may have had a mild late asthmatic reaction not detected by the measurement of $\mathrm{FEV}_{1}$.

This case report underscores the need for doctors to always be conscious of new agents responsible for occupational asthma so that the diagnosis can be confirmed and the patient removed from exposure.

The study is from the Respiratory Division, Vancouver General Hospital, Department of Medicine, University of British Columbia, Vancouver BC, Canada and is supported by the
Workers' Compensation Board of British Columbia. Henry Chan is the recipient of a scholarship from the Canadian Lung Association and the FRSQ.

Request for reprints to: Johanne Côté MD, Centre de Pneumologie, Hôpital Laval, 2725 chemin Ste-Foy, Sainte-Foy, Québec, Canada G1V 4 G5.

1 Hargreave FE. Extrinsic allergic alveolitis. Can Med Assoc J 1973;108:1150-4.

2 Avilla $\mathrm{R}$, Lacey $\mathrm{J}$. The role of penicillium frequentans in suberosis. Clin Allergy 1974;4:109-17.

3 Emmanuel DA, Wenzel FJ, Bowerman CJ, Lawton BR. Farmer's lung, clinical, pathologic and immunologic study of 24 patients. Am J Med 1974;274:1413-6.

4 Emmanuel DA, Wenzel FJ, Lawton BR. Pneumonitis due to Cryptostroma corticale (maple bark disease). $N$ Eng $J$ Med 1966;37:392-7.

5 Chan-Yeung M. State of the art on occupational asthma. Am Rev Respir Dis 1986;133:686-703.

6 Klaustermeyer WB, Bardana EJ, Hale FC. Pulmonary hypersensitivity to Alternaria and Aspergillus in baker's asthma. Clin Allergy 1977;7:227-33.

7 Ceska M, Eriksson R, Varga JM. Radioimmunosorbent assay of allergens. $J$ Allergy Clin Immunol 1972;49:1-9.

8 Lam S, Wong R, Yeung $M$. Non-specific bronchial reactivity in occupational asthma. J Allergy Clin Immunol 1979;63:28-34.

9 Morris JF, Koski A, Johnson LC. Spirometric standards for healthy non-smoking adults. Am Rev Respir Dis 1971;103: $57-67$.

10 ATS statement. Snowbird workshop in standardization of spirometry. Am Rev Respir Dis 1979;119:831-8. 